\title{
Serum Level of microRNA-375-3p Is Not a Reliable Biomarker of Teratoma
}

\author{
GAZANFER BELGE ${ }^{1 *}$, FRANCESCA GROBELNY ${ }^{1 *}$, CORD MATTHIES ${ }^{2}$, \\ ARLO RADTKE ${ }^{1}$ and KLAUS-PETER DIECKMANN ${ }^{3}$ \\ ${ }^{1}$ Faculty of Biology and Chemistry, University of Bremen, Bremen, Germany; \\ ${ }^{2}$ Department of Urology, Bundeswehrkrankenhaus Hamburg, Hamburg, Germany; \\ ${ }^{3}$ Department of Urology, Asklepios Klinik Altona, Hamburg, Germany
}

\begin{abstract}
Background/Aim: Clinical management of testicular germ cell tumours (GCT) is based upon the measurement of serum tumour markers. Recent studies have shown that the microRNA-371a-3p is a sensitive and specific serum biomarker for all subgroups of GCT, except teratoma. To close the diagnostic gap relating to teratoma, serum levels of microRNA375-3p have recently been suggested to represent a specific serum marker of this histological subgroup. In the present study, we tested this hypothesis. Materials and Methods: miRNA expression was analysed in serum of 21 GCT patients with teratoma, twelve patients with other GCT, and twelve male controls using the qPCR method. Results: The serum miR-375$3 p$ levels of teratoma patients were not different from other GCT patients or controls. The ROC analysis revealed an AUC of 0.524 for the discrimination between teratoma and other pathologies. Conclusion: The miR-375-3p does probably not qualify for a useful serum biomarker to distinguish teratoma from other GCTs and from controls.
\end{abstract}

The clinical management of testicular germ cell tumours (GCTs) greatly rests on the measurement of the classical serum tumour markers beta human chorionic gonadotropin (bHCG), alpha fetoprotein (AFP) and lactate dehydro-genase (LDH) (1). A major limitation of these biomarkers is that they are differently expressed in the various histological subgroups of GCTs. In seminoma, the most frequent subgroup, bHCG and LDH are expressed in roughly $30 \%$ of cases, while AFP is not (2). In

This article is freely accessible online.

*These Authors contributed equally to this study.

Correspondence to: Gazanfer Belge, Faculty of Biology and Chemistry, University of Bremen, Leobener Straße 2, 28359 Bremen, Germany. Tel: +49 42121861570, e-mail: belge@uni-bremen.de

Key Words: microRNA, miR-375-3p, teratoma, testicular germ cell tumour, serum, biomarkers. nonseminoma, the other main subgroup, all three markers are expressed in $30-60 \%$ of cases $(3,4)$. However, nonseminomas may comprise of four histologic subtypes each of which having its specific marker pattern. As several histological subtypes may occur simultaneously in one nonseminomatous tumour (5), a variety of marker patterns is possible in the entire group of nonseminomas (2). Yolk sac tumours usually express AFP, only. Choriocarcinoma specifically expresses bHCG. Embryonal carcinoma usually does not express any marker, but may show AFP elevations in isolated cases. Teratoma the most differentiated subtype does not express any of the markers (4). $\mathrm{LDH}$ is an unspecific marker that may be elevated in any of the subtypes of GCT except for teratoma. Recently, serum levels of microRNA-371a-3p (miR-371a-3p) have been shown to represent a novel serum biomarker of GCT with much higher sensitivity and specificity than the three classical markers (6). Importantly, this new marker is likewise informative for seminoma and nonseminoma. However, miR-371a-3p levels are not elevated in cases with teratoma (7). As the presence of teratoma in metastatic deposits is a challenge in clinical decisionmaking in many cases, it would clearly be beneficial to have one serum biomarker that is associated with the presence of this particular GCT subtype. In a recent publication on the role of miRs in GCTs, microRNA-375 was reported to be present in the tissue of teratoma. Although this miR had, so far, not been evaluated in serum it was considered a candidate biomarker for this particular subtype of GCTs (8). We, therefore, looked to the presence of this miR in the serum of patients with teratoma. Our aim was to test the hypothesis that serum levels of miR-375-3p might represent a valuable serum biomarker of teratoma.

\section{Materials and Methods}

Patients. Serum samples of 21 patients (median age: 34.5) with teratoma were examined for miR-375-3p (miR-375-3p) expression before treatment. Sixteen patients had testicular primary tumours consisting of pure teratoma without metastases [clinical stage (CS) 1]. Three patients had residual retroperitoneal masses after chemotherapy surgically proven to consist of teratoma only (CS2). Two other patients 
had both retroperitoneal and mediastinal metastases that were surgically resected and likewise proven to consist of pure teratoma (CS3). The patients were retrospectively recruited for the present study and serum samples for analysis were derived from a serum bank. All of the patients had participated in previous studies on miR-371a-3p (7, 9). Serum samples from twelve patients (median age: 36.0 ) with nonmalignant scrotal diseases (hydrocele, epididymitis) served as controls. We also analysed twelve serum samples of patients with other GCT (median age: 34.5 years). Individual data regarding the patients and controls are given in Table I.

All patients gave informed consent. The study has been ethically approved by Ärztekammer Bremen (\#301, decisions Jul 08 and Oct $08,2015)$. All study activities had been conducted according to the Declaration of Helsinki of the World Medical Association (as amended by the 64th General Assembly, 2013).

Laboratory methods. Blood samples were collected in serum separations tubes (Sarstedt, Nümbrecht, Germany) and kept at room temperature for $1 \mathrm{~h}$ to allow for complete coagulation after blood aspiration. The blood samples were centrifuged for $10 \mathrm{~min}$ at 2,500 $\times$ $g$ to separate serum, and aliquots were stored at $-80^{\circ} \mathrm{C}$ until examination for study purposes. Serum levels of miR-375-3p were measured by quantitative real-time polymerase chain reaction (qPCR) as reported earlier for other miRs $(10,11)$. Briefly, total RNA was extracted from $200 \mu \mathrm{l}$ serum using the miRNeasy Mini Kit (Qiagen, Hilden, Germany). Reverse transcription (RT) was performed using the TaqMan MicroRNA Reverse Transcription Kit (Applied Biosystems, Darmstadt, Germany). The RT product was preamplified, and levels of miR-375-3p (assay ID: 000564) and miR-30b-5p (assay ID: 000602) were measured by qPCR with TaqMan miRNA assays using the Applied Biosystems 7500 real-time PCR System (Applied Biosystems, Darmstadt, Germany). All PCR experiments were carried out in triplicate using the FastStart Universal Probe Master (Roche, Mannheim, Germany). Cycle threshold (Ct) values were normalised to miR-30b-5p as an internal control, and the relative quantity (RQ) was calculated using the $2-\Delta \Delta \mathrm{Ct}$ method (12).

The miR-375-3p expression of the various groups is presented as median with interquartile ranges (IQR). The statistical evaluation was carried out with SPSS. Receiver operating characteristics (ROC) analysis was performed to assess the ability of miR-375-3p serum levels to differentiate between teratoma and other conditions. For the analysis of differences between two independent variables, the Mann-Whitney $U$-test was used. The null hypothesis was that there would be no differences between patient groups and controls and the alternative hypothesis was that miR-375-3p expression would be at variance among the groups. Significance was assumed at $p<0.05$.

\section{Results}

The median relative miR-375-3p expression in 21 patients with teratoma was $4,390.0(\mathrm{IQR}=15,284.2)$, compared to a median expression of 2,800.1 ( $\mathrm{IQR}=6,513.5)$ in 12 patients with GCT, other than teratoma, and 6,163.8 (IQR=10,554.7) in 12 patients with non-malignant testicular disease (Figure 1). The differences between these groups were not significant. Stratified for clinical stage the CS1 teratoma patients $(n=16)$ had a median relative miR-375-3p expression of $5,071.3$ $(\mathrm{IQR}=15,954.6)$. The $\mathrm{CS} 2(\mathrm{n}=3)$ and $\mathrm{CS} 3(\mathrm{n}=2)$ patients had a median expression of $4,359.7$ and $13,861.7$, respectively (Figure 2). Again, these differences were not significant.

The discriminative power of $\mathrm{miR}-375-3 \mathrm{p}$ as a serum marker for teratoma was assessed with ROC analysis by comparing the 21 teratoma patients with the 24 patients without teratoma (patients with other GCTs and patients with non-malignant testicular disease grouped together). The area under the curve (AUC) was 0.524, which was not significantly different from an AUC of 0.5 , the area of chance results (Figure 3).

\section{Discussion}

The hypothesis that serum levels of miR-375-3p might be a valuable biomarker of teratoma as forwarded by Shen et al. (8) is not supported by the present study. In particular, the median serum level of $\mathrm{miR}-375-3 \mathrm{p}$ found in teratoma patients was not different from the median levels found in other GCT patients (those without teratoma) and healthy males, respectively. Moreover, if one assumed that the miR was associated with teratomatous tumours then higher expression rates in serum would have been expected in patients with large and bulky tumours than in those with small tumours. However, as shown herein, bulky teratomatous tumours (clinical stages 2-3) did not express significantly higher serum levels than patients with clinical stage 1 . Accordingly, the sensitivity and specificity of serum miR-375-3p levels to detect teratoma are very low as shown in the ROC analysis that revealed an AUC of only 0.524, which is not significantly different from null findings with an AUC of 0.5. All in all, according to the present findings, miR-375-3p levels are probably not capable of discriminating teratoma from other pathologies.

Our results seem contradictory to the results of Shen and colleagues (8), especially since a correlation between intratumor and serum levels has been shown for miR-375-3p and other miRs $(13,14)$. However, the reason for the low discriminative ability of miR-375-3p as documented in our study was not the lack of expression in teratoma serum but rather the equally high expression in serum of other GCT patients and controls. Modified expression of miR-375-3p is known in other cancer types like esophageal squamous cell carcinoma and osteosarcoma, where a downregulation of that $\mathrm{miR}$ is indicative for poor prognosis $(13,15)$.

A serum biomarker sensitive and specific for teratoma would be particularly valuable in the assessment of residual tumour masses after chemotherapy of advanced nonseminomatous GCT. Currently, guide-lines recommend surgical resection of any residual mass that is larger than 1 $\mathrm{cm}$ (1). However, the histological evaluation of surgical specimens of these cases revealed that in approximately 40$50 \%$ the residual masses consisted of necrosis or fibrosis only, while $30-40 \%$ had teratoma and only $10-20 \%$ had 
Table I. Clinical data of serum from the analyzed patients.

\begin{tabular}{|c|c|c|c|c|c|c|c|}
\hline Patient ID & Age (yrs) & Histology & Clinical stage & $\beta-\mathrm{HCG}(\mathrm{mIE} / \mathrm{ml})$ & $\mathrm{AFP}(\mathrm{ng} / \mathrm{ml})$ & LDH (U/1) & RQ miR-375-3p \\
\hline 1 & 23 & Teratoma & CS1 & $<2$ & $<5.8$ & $<250$ & $103,552.29$ \\
\hline 2 & 58 & Teratoma & CS1 & 0.1 & 3.01 & 147 & $21,027.65$ \\
\hline 3 & 24 & Teratoma & $\mathrm{CS} 1$ & 1.2 & 1.31 & 166 & $8,135.41$ \\
\hline 4 & 34 & Teratoma & CS1 & 1.2 & 102.73 & 183 & $4,389.98$ \\
\hline 5 & 22 & Teratoma & CS1 & 2.3 & 1.97 & n.a. & $20,311.37$ \\
\hline 6 & 34 & Teratoma & CS1 & 1.2 & 1.58 & n.a. & $5,752.61$ \\
\hline 7 & 41 & Teratoma & $\mathrm{CS} 1$ & 0.6 & 2.5 & n.a. & $1,897.65$ \\
\hline 8 & 21 & Teratoma & $\mathrm{CS} 1$ & 0.6 & 1.8 & n.a. & 393.44 \\
\hline 9 & 35 & Teratoma & $\mathrm{CS} 1$ & 0.1 & 4.6 & 237 & $2,469.49$ \\
\hline 10 & n.a & Teratoma & CS1 & $<2$ & $<5.8$ & $<250$ & $10,085.54$ \\
\hline 11 & 29 & Teratoma & $\mathrm{CS} 1$ & 0.7 & 1 & 147 & 177.29 \\
\hline 12 & 19 & Teratoma & $\mathrm{CS} 1$ & 2.3 & 4 & 150 & $1,595.73$ \\
\hline 13 & 22 & Teratoma & CS1 & $<1$ & 58.9 & 191 & $45,073.75$ \\
\hline 14 & 52 & Teratoma & CS1 & $<0,1$ & 3 & 246 & $2,998.45$ \\
\hline 15 & 43 & Teratoma & CS1 & 1.2 & 4.7 & 158 & $2,009.84$ \\
\hline 16 & 37 & Teratoma & CS1 & n.a. & n.a. & n.a. & $10,586.95$ \\
\hline 17 & 38 & Teratoma & $\mathrm{CS} 2$ & n.a. & n.a. & n.a. & 126.24 \\
\hline 18 & 38 & Teratoma & $\mathrm{CS} 2$ & 1.2 & 4.08 & n.a. & $4,359.66$ \\
\hline 19 & 27 & Teratoma & $\mathrm{CS} 2$ & n.a. & n.a. & n.a. & $14,164.58$ \\
\hline 20 & 43 & Teratoma & $\mathrm{CS} 3$ & n.a. & n.a. & n.a. & $3,061.45$ \\
\hline 21 & 42 & Teratoma & $\mathrm{CS} 3$ & $<2$ & 2.7 & 188 & $24,661.96$ \\
\hline 22 & 50 & S & CS1 & 1.2 & 2.6 & 164 & $1,652.00$ \\
\hline 23 & 40 & $\mathrm{~S}$ & CS1 & 1.2 & 4.3 & 137 & $2,916.45$ \\
\hline 24 & 35 & $\mathrm{~S}$ & CS1 & 1.2 & 2.4 & 2.5 & $17,438.64$ \\
\hline 25 & 44 & $\mathrm{~S}$ & CS1 & 1.2 & 2.1 & 226 & $2,646.74$ \\
\hline 26 & 25 & NS & CS1 & 1.2 & 3.9 & 260 & $3,875.05$ \\
\hline 27 & 21 & NS & CS1 & 1.48 & 1161 & 152 & $2,134.97$ \\
\hline 28 & 36 & $\mathrm{~S}$ & CS1 & 1.2 & 1.4 & 216 & $1,629.26$ \\
\hline 29 & 25 & NS & $\mathrm{CS} 2$ & 16.1 & 5.1 & 215 & $1,287.18$ \\
\hline 30 & 34 & $\mathrm{~S}$ & CS1 & 1.2 & 14.01 & 232 & $6,251.56$ \\
\hline 31 & 38 & S & $\mathrm{CS} 2$ & 0.47 & 3.46 & 245 & $28,724.62$ \\
\hline 32 & 33 & $\mathrm{~S}$ & $\mathrm{CS} 1$ & 1.64 & 5.49 & 254 & $8,964.45$ \\
\hline 33 & 28 & NS & CS2 & 0.81 & 2.17 & 246 & $2,683.69$ \\
\hline 34 & 67 & Control & Healthy & 1.35 & 2.6 & 211 & $7,967.99$ \\
\hline 35 & 49 & Control & Healthy & 2.19 & 7.9 & 110 & $3,444.31$ \\
\hline 36 & 23 & Control & Healthy & 1.2 & 1.9 & 153 & $1,509.65$ \\
\hline 37 & 21 & Control & Healthy & n.a. & n.a. & n.a. & $10,960.30$ \\
\hline 38 & 67 & Control & Healthy & 1.2 & 2 & 147 & $2,222.55$ \\
\hline 39 & 31 & Control & Healthy & 1.2 & 2.5 & 151 & $3,633.14$ \\
\hline 40 & 41 & Control & Healthy & 1.2 & 1.6 & 242 & $4,359.66$ \\
\hline 41 & 33 & Control & Healthy & 1.2 & 3 & 204 & $2,401.97$ \\
\hline 42 & 26 & Control & Healthy & n.a. & n.a. & n.a. & $8,719.32$ \\
\hline 43 & 18 & Control & Healthy & n.a. & n.a. & n.a. & $30,786.28$ \\
\hline 44 & 55 & Control & Healthy & n.a. & n.a. & n.a. & $13,969.57$ \\
\hline 45 & 39 & Control & Healthy & n.a. & n.a. & n.a. & $14,263.10$ \\
\hline
\end{tabular}

CS: Clinical stage; S: seminoma; NS: non-seminoma; $\beta$-HCG: $\beta$-subunit of human chorionic gonatropin; AFP: alpha-fetoprotein; LDH: lactate dehydrogenase; RQ: relative quantity in relation to a reference sample; n.a.: not available.

viable residual cancer $(16,17)$. By retrospective analysis it becomes clear that $50 \%$ of these major surgical procedures are being performed without any clear benefit for the patient because only necrosis is excised. A recent study showed that all of the patients with viable cancer in the resected specimen had elevated levels of miR-371a-3p preoperatively (18). Unfortunately, it is currently not possible to differentiate those with teratoma from those with necrosis/fibrosis prior to surgery. Therefore, residual masses with negative miR371a-3p levels after chemotherapy remain indeterminate because they may have either teratoma or necrosis. Clinically, teratoma does definitely require surgical excision while necrosis/fibrosis could be left untreated. Thus, no clear therapeutic decision regarding surgery can be based on the 


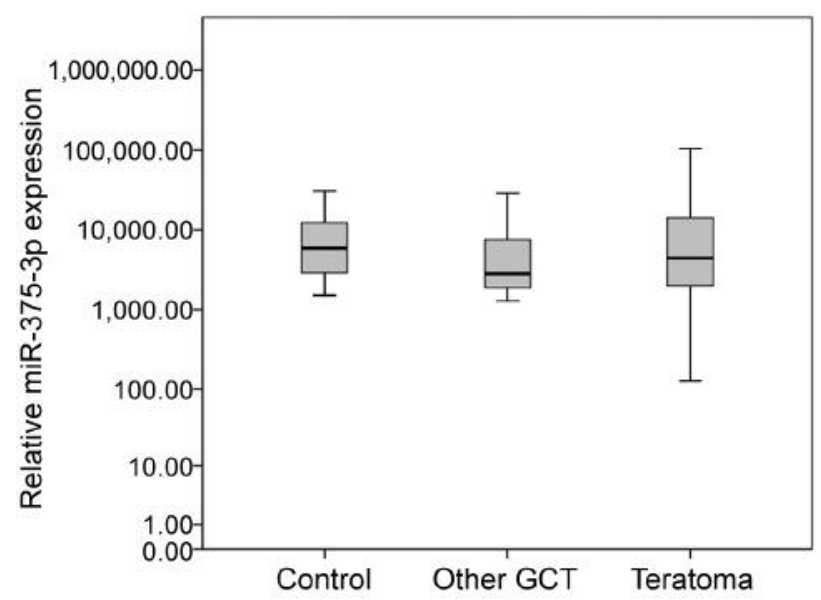

Figure 1. Boxplots of the relative miR-375-3p serum expression. Expression in serum of $n=12$ patients with non-malignant testicular disease (control), $n=12$ patients with testicular germ cell tumours (GCT) other than teratoma, and $n=21$ patients with teratoma was compared. The y-axis is plotted in a logarithmic scale.

miR-371a-3p test in that setting. A great deal of enthusiasm evolved among clinicians caring for GCT patients when the hypothesis of miR-375 being informative for teratoma was forwarded. The results of the present study, however, probably disprove that hypothesis.

The present study is, of course, not without limitations. The small sample size of only 21 patients with teratoma does leave the possibility of chance results. On the other hand, GCT as such is a rare disease and the subgroup of pure teratoma is even rarer. Therefore, the sample size of $n=21$ appears at least acceptable for the purpose of this study particularly in light of the clear-cut results documented herein. Also, the retrospective study design with the use of serum samples from a serum bank may induce chance effects. Teratoma may comprise of various histological features such as cartilage or bone structures, muscular tissue or gland structures and other histological formations (19). We did not perform a histological subclassification of our patients. So, it is at least conceivable that for some particular subtypes of teratoma the miR-375-3p may indeed be an appropriate marker.

In conclusion, the miR-375-3p does not qualify for a serum biomarker to distinguish teratoma from other GCTs and from controls. Therefore, an informative biomarker of teratoma is still missing. However, we have only very recently started to understand that serum levels of miRs may serve as disease markers $(20,21)$. Currently, more than 2000 miRs have been identified in the human body with an ever-growing number.

In the future, large scale micro-array studies may possibly reveal novel markers that may also be sensitive for

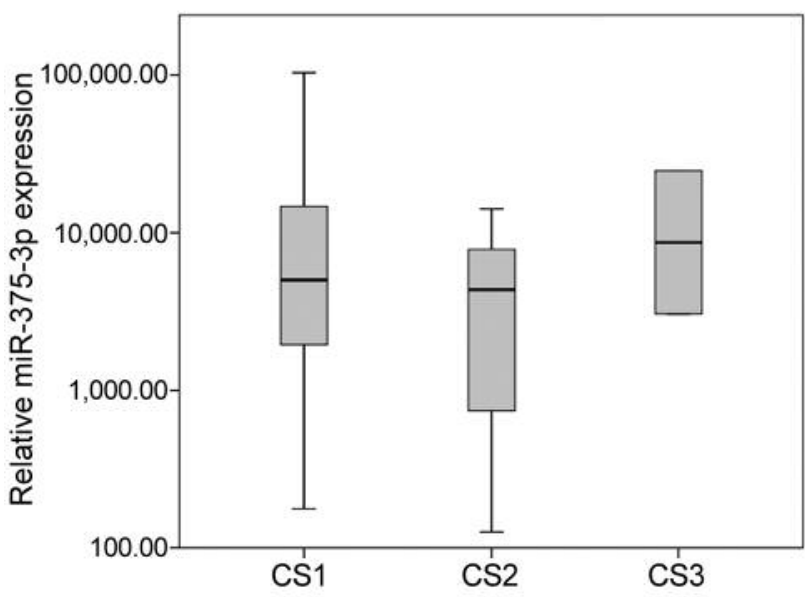

Figure 2. Boxplots of the miR-375-3p serum expression in teratoma patients with different clinical stages (CS). Expression was compared between $n=16$ patients with $C S 1, n=3$ patients with CS2, and $n=2$ CS 3 patients. The y-axis is plotted in a logarithmic scale.

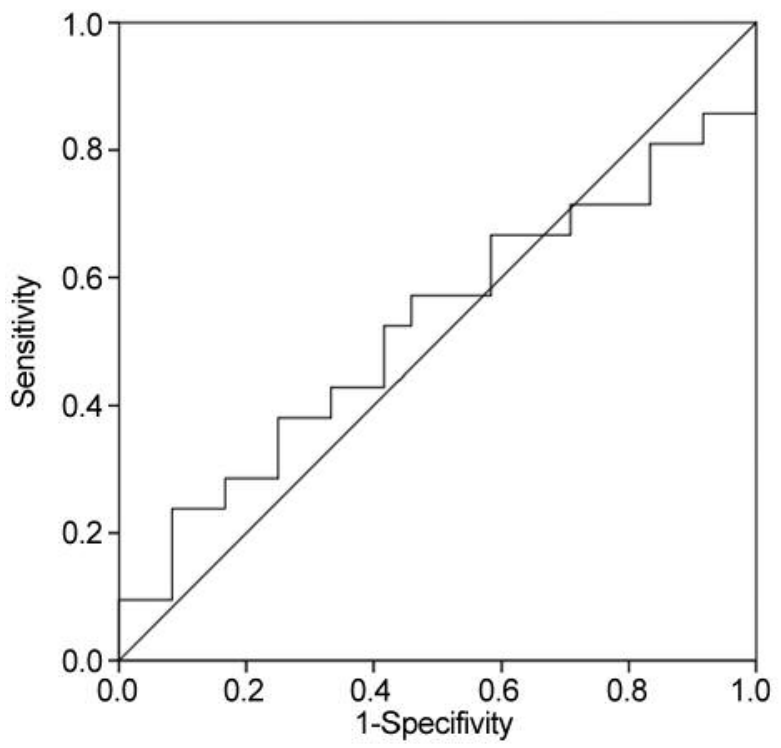

Figure 3. ROC curve representing the ability of serum miR-375-3p to discriminate between teratoma $(n=21)$ and other conditions $(n=24)$. The AUC is 0.524 .

teratoma. A possible candidate being a part of the micro array would be the microRNA-301, which is expressed in differentiated tissues like teratoma (22). An additional option for classification between different GCT subtypes is gene expression profiling to find specific gene signatures for teratoma (23). 


\section{Conflicts of Interest}

KPD and GB each possess $12.9 \%$ ownership shares of miRdetect $\mathrm{GmbH}$, Bremen, a start-up company aiming to develop a commercially available test for measuring miRs in serum. miRdetect holds a patent for the measurement of miR in body fluids at the limit of detection. AR is an employee of miRdetect $\mathrm{GmbH}$, Bremen since the beginning of 2019. All other authors declare no competing interests towards this report.

\section{Authors' Contributions}

G.B., A.R., K.P.D. designed the study; K.P.D., C.M. patient enrolment, G.B., A.R., F.G. executed the experiments, G.B., A.R., K.P.D., F.G. analysis and interpretation of the data; A.R., F.G. statistical analysis; G.B., A.R., K.P.D., F.G., C.M. drafting of manuscript. All authors critically revised and finally approved the manuscript.

\section{Acknowledgements}

The Authors gratefully acknowledge the technical assistance of the laboratory staffs of the University of Bremen and Asklepios Klinik Altona, Hamburg.

\section{Funding}

The present study received support from Wilhelm Sander Stiftung, München (No, 2014.178.2). The sponsor had no role in study design; in the collection, analysis and interpretation of data; in the writing of the report; and in the decision to submit the article for publication.

\section{References}

1 Albers P, Albrecht W, Algaba F, Bokemeyer C, Cohn-Cedermark G, Fizazi K, Horwich A, Laquana MP, Nicolai N and Oldenburg J: Guidelines on Testicular Cancer: 2015 Update. Eur Urol 68: 1054-1068, 2015. PMID: 26297604. DOI: 10.1016/j.eururo. 2015.07.044

2 Dieckmann KP, Simonsen-Richter H, Kulejewski M, Anheuser $\mathrm{P}$, Zecha $\mathrm{H}$, Isbarn $\mathrm{H}$ and Pichlmeier $\mathrm{U}$ : Serum tumour markers in testicular germ cell tumours: frequencies of elevated levels and extents of marker elevation are significantly associated with clinical parameters and with response to treatment. BioMed Res Int 2019: 5030349, 2019. PMID: 31275973. DOI: 10.1155/ 2019/5030349

3 Murray MJ, Huddart RA and Coleman N: The present and future of serum diagnostic tests for testicular germ cell tumours. Nat Rev Urol 3(12): 715-725, 2016. PMID: 27754472. DOI: 10.1038/nrurol.2016.170

4 Leão R, Ahmad AE and Hamilton RJ: Testicular cancer biomarkers: A role for precision medicine in testicular cancer. Clin Genitourin Cancer 17(1): e176-e183, 2018. PMID: 30497810. DOI: $10.1016 /$ j.clgc.2018.10.007

5 Stang A, Rusner C, Trabert B, Oosterhuis JW, McGlynn KA and Heidinger O: Incidence of testicular tumor subtypes according to the updated WHO classification, North Rhine-Westphalia, Germany, 2008-2013. Andrology 7(4): 402-407, 2019. PMID: 30578617. DOI: $10.1111 /$ andr.12565
6 Lobo J, Gillis AJM, Jerónimo C, Henrique R and Looijenga LHJ: Human germ cell tumors are developmental cancers: Impact of epigenetics on pathobiology and clinic. Int J Mol Sci 20(2): pii: E258, 2019. PMID: 30634670. DOI: 10.3390/ ijms 20020258

7 Dieckmann KP, Radtke A, Geczi L, Matthies C, Anheuser P, Eckardt U, Sommer J, Zengerling F, Trenti E, Pichler R, Belz H, Zastrow S, Winter A, Melchior S, Hammel J, Kranz J, Bolten M, Krege S, Haben B, Loidl W, Ruf CG, Heinzelbecker J, Heidenreich A, Cremers JF, Oing C, Hermanns T, Fankhauser CD, Gillessen S, Reichegger H, Cathomas R, Pichler M, Hentrich M, Eredics K, Lorch A, Wülfing C, Peine S, Wosniok W, Bokemeyer C and Belge G: Serum levels of microRNA371a-3p (M371 Test) as a new biomarker of testicular germ celltumors: Results of a prospective multicentric study. J Clin Oncol 37(16): 1412-1423, 2019. PMID: 30875280. DOI: 10.1200/ JCO.18.01480

8 Shen H, Shih J, Hollern DP, Wang L, Bowlby R, Tickoo SK, Thorsson V, Mungall AJ, Newton Y, Hedge AM, Armenia J, Sánchez-Vega F, Pluta J, Pyle LC, Mehra R, Reuter VE, Godoy G, Jones J, Shelley CS, Feldman DR, Vidal DO, Lessel D, Kulis T, Cárcano FM, Leraas KM, Lichtenberg TM, Brooks D, Cherniack AD, Cho J, Heiman DI, Kasaian K, Liu M, Noble MS, Xi L, Zhang H, Zhou W, ZenKlusen JC, Hutter CM, Felau I, Zhang J, Schultz N, Getz G, Meyerson M, Stuart JM; Cancer Genome Atlas Research Network, Akbani R, Wheeler DA, Laird PW, Nathanson KL, Cortessis VK and Hoadley KA: Integrated molecular characterization of testicular germ cell tumors. Cell Rep 23(11): 3392-3406, 2018. PMID: 29898407. DOI: 10.1016/j.celrep.2018.05.039

9 Dieckmann KP, Radke A, Spiekermann M, Balks T, Matthies C, Becker P, Ruf C, Oing C, Oechsle K, Bokemeyer C, Hammel J, Melchior S, Wosniok W and Belge G: Serum Levels of MicroRNA 371a-3p: A sensitive and specific new biomarker for germ cell tumors. Eur Urol 71(2): 213-220, 2017. PMID: 27495845. DOI: $10.1016 /$ j.eururo.2016.07.029

10 Spiekermann M, Belge G, Winter N, Ikogho R, Balks T, Bullerdiek $J$ and Dieckmann KP: MicroRNA miR-371a-3p in serum of patients with germ cell tumours: evaluations for establishing a serum biomarker. Andrology 3(1): 78-84, 2015. PMID: 25187505. DOI: 10.1111/j.2047-2927.2014.00269.x

11 Spiekermann M, Diekmann KP, Balks T, Bullerdiek J and Belge $\mathrm{G}$ : Is relative quantification dispensable for the measurment of microRNAs as serum biomarkers in germ cell tumors? Anticancer Res 35(1): 117-122, 2015. PMID: 25550541.

12 Livak KJ and Schmittgen TD: Analysis of relative gene expression data using real-time quantitative PCR and the 2(Delta Delta C(T)) Method. Methods 25(4): 402-408, 2001. PMID: 11846609. DOI: 10.1006/meth.2001.1262

$13 \mathrm{Wu}$ C, Li M, Hu C and Duan H: Clinical significance of serum miR-223, miR-25 and miR-375 in patients with esophageal squamous cell carcinoma. Mol Biol Rep 41: 1257-1266, 2014. PMID: 24390317. DOI: 10.1007/s11033-013-2970-Z

14 Guo J, Meng R, Yin Z, Li P, Zhou R, Zhang S, Dong X, Liu L and Wu G: A serum microRNA signature as a prognostic factor for patients with advanced NSCLC and its association with tissue microRNA expression profiles. Mol Med Rep 13: 46434653, 2016. PMID: 27081922. DOI: 10.3892/mmr.2016.5114

15 Liu W, Zhao XT, Zhang YJ, Fang GW and Xue Y: MicroRNA375 as a potential serum biomarker for the diagnosis, prognosis, 
and chemosensitivity prediction of osteosarcoma. J Intl Med Res 46(3): 975-983, 2018. PMID: 29115164. DOI: 10.1177/ 0300060517734114

16 Steyerberg EW, Keizer HJ, Fosså SD, Sleijfer DT, Toner GC, Schraffordt Koops H, Mulders PF, Messemer JE, Ney K, Donohue JP, Bajorin D, Stoter G, Bosl GJ and Habbema JDF: Prediction of residual retroperitoneal mass histology after chemotherapy for metastatic nonseminomatous germ cell tumor: multivariate analysis of individual patient data from six study groups. J Clin Oncol 13(5): 1177-1187, 1995. PMID: 7537801. DOI: $10.1200 / J C O .1995 .13 .5 .1177$

17 Heidenreich A, Thuer D and Polyakov S: Postchemotherapy retroperitoneal lymph node dissection in advanced germ cell tumours of the testis. Eur Urol 53(2): 260-272, 2008. PMID: 18045770. DOI: $10.1016 /$ j.eururo.2007.10.033

18 Leão R, van Agthoven T, Figueiredo A, Jewett MAS, Fadaak K, Sweet J, Ahmad AE, Anson-Cartwright L, Chung P, Hansen A, Warde P, Castelo-Branco P, O'Malley M, Bedard PL, Looijenga LHJ and Hamilton RJ: Serum miRNA predicts viable disease post-chemotherapy in testicular non-seminoma germ cell tumor patients. J Urol 200(1): 126-135, 2018. PMID: 29474847. DOI: 10.1016/j.juro.2018.02.068

19 Idrees MT, Ulbright TM, Oliva E, Young RH, Montironi R, Egevad L, Berney D, Srigley JR, Epstein JI, Tickoo SK and the Members of the International Society of Urological Pathology Testicular Tumour Panel: The World Health Organization 2016 classification of testicular non-germ cell tumours: a review and update from the International Society of Urological Pathology Testis Consultation Panel. Histopathology 70(4): 513-521, 2017. PMID: 27801954. DOI: 10.1111/his.13115
20 Ellinger J and Muller SC: MicroRNAs: A Novel Non-Invasive Biomarker for Patients with Urological Malignancies. Curr Pharm Biotechnol 15: 486-491, 2014. PMID: 24846060. DOI: $10.2174 / 1389201015666140519124909$

21 Batool A, Liu XM, Zhang CL, Hao CF, Chen SR and Liu YX: Recent advances in the regulation of testicular germ cell tumors by microRNAs. Front Biosci (Landmark Ed) 24: 765-776, 2019. PMID: 30844711. DOI: 10.2741/4749

22 Bezan A, Gerger A and Pichler M: MicroRNAs in testicular cancer: Implications for pathogenesis, diagnosis, prognosis and therapy. Anticancer Res 34(6): 2709-2744, 2014. PMID: 24922631.

23 Biermann K, Heukamp LC, Steger K, Zhou H, Franke FE, Sonnack V, Brehm R, Berg J, Bastian PJ, Müller SC, WangEckert L and Buettner R: Genome-wide expression profiling reveals new insights into pathogenesis and progression of testicular germ cell tumors. Cancer Genomics Proteomics 4(5): 359-368, 2007. PMID: 17993720.
Received September 5, 2019

Revised October 5, 2019

Accepted November 5, 2019 